\title{
EDITORIAL
}

\section{Patients with acute coronary syndrome should start a statin while still in hospital}

\section{G Isles}

Despite well documented clinical benefit of statins in patients with coronary heart disease, there remains a significant "treatment gap" between those patients in whom treatment is indicated and those who actually receive it

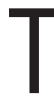
wo papers in this issue of Heart address the low uptake of statins. The first, by Reid and colleagues, is a cross sectional analysis of data from the Health Survey for England 1998 of 760 adults with coronary heart disease which shows that the elderly (over 65 years), smokers, and patients with angina are less likely to be given statins than younger patients, non-smokers, and those with previous myocardial infarction. ${ }^{1}$ The second paper, by Steg and associates, is an analysis of 3092 patients admitted with acute coronary syndromes to 390 hospitals across Europe which shows, inter alia, prescription rates for statins at discharge were higher among patients undergoing coronary angiography or percutaneous intervention than in patients treated conservatively. ${ }^{2}$ In the first study, which was conducted in primary care, only $25.4 \%$ of eligible subjects were taking lipid lowering medication. More lipid lowering drugs were prescribed in the second study, which was hospital based, but still only $42.9 \%$ of patients were treated appropriately. The authors of both studies concluded that we discriminate for or against certain patient characteristics when we prescribe statins. An equally clear message from both papers is that despite well documented clinical benefit of statins in patients with coronary heart disease, there remains a significant "treatment gap" between those patients in whom treatment is indicated and those who actually receive it.

\section{CONTINUING LOW UPTAKE OF STATINS}

The scale of the challenge is daunting. An observational study of statin prescribing in 288 general practices in England and Wales showed that of those patients with a general practitioner diagnosis of ischaemic heart disease, only $13.3 \%$ of men and $8.2 \%$ of women received a prescription for a statin in 1996. ${ }^{3}$ In a more recent UK survey of 24431 patients with coronary heart disease, conducted in primary care in 1997 and 1998, a third of the men and more than half of the women had never had a cholesterol measurement, $75 \%$ of those whose cholesterol had been measured had total cholesterol $>5 \mathrm{mmol} / \mathrm{l}$, and only $16 \%$ of patients were receiving statin treatment. ${ }^{4}$
The Americans may prescribe more statins than we do, but even they might have difficulty in meeting the National Service Framework targetnamely, that $80-90 \%$ of coronary heart disease patients should be taking statins. ${ }^{5}$ Lipid lowering medications were part of the discharge regimen in only $31.7 \%$ of 138001 patients with acute myocardial infarction discharged from 1470 US hospitals in 1998 and 1999. In a multivariate analysis, factors independently related to lipid lowering use included history of hyperlipidaemia, cardiac catheterisation during hospitalisation, care provided at a teaching hospital, use of a $\beta$ blocker, and smoking cessation counselling. Lipid lowering medications were given less often to patients who were older (65-74 years), those with a history of hypertension, and those undergoing coronary bypass surgery. ${ }^{6}$

\section{BARRIERS TO IMPLEMENTATION}

So why have robust evidence and best practice guidelines failed so far to achieve the National Service Framework targets? Resistance to change on the part of the physician or general practitioner is often cited as a reason why valid research based recommendations and clinical guidance are not routinely adopted in practice. Ten years ago, lack of interest among doctors may have been a barrier to prescribing prophylactic drugs following myocardial infarction, but this seems less likely now given the high profile accorded to secondary prevention of coronary heart disease by the National Health Service both locally and nationally. The results of EUROASPIRE II suggest that progress is being made in this area, albeit more slowly than most of us would wish. ${ }^{7}$ Lack of resources are also usually quoted as a barrier to implementing guidelines. The cost of treating coronary heart disease patients with statins in 1999 was estimated to lie between $£ 5100$ and $£ 8200$ per life year gained. ${ }^{8}$ The authors argued that this was as cost effective as many other treatments in wide use-for example, bypass surgery for men with severe angina and three vessel disease. ${ }^{8}$ Statins are certainly more cost effective than the measures taken to improve safety of rail travel after the Hatfield crash. If as a country we can afford one then why not the other?

\section{FAILURE TO COMPLY}

Another important barrier is that a significant minority of the public may not wish or be able to comply. This politically incorrect observation is supported by the results of several recent studies which suggest that patients in the UK may be less willing than their counterparts in the US and 
Europe to change their lifestyles and take prophylactic medication. ${ }^{9}$ Failure to adhere to advice and treatment does not necessarily imply a deliberate wish on the part of the patient to sabotage the efforts of clinicians in reducing coronary risk, but reflects a complex web of choices and influences on patients' behaviour. A wealth of research in the compliance and adherence field has identified factors influencing the likelihood that patients will engage in behavioural change: these include knowledge (though it is quite clear that knowledge alone does not change behaviour), health beliefs, readiness to change, perception of benefits, social and cultural factors, and the doctor-patient relationship. Successful secondary prevention will need to take all of these into account. ${ }^{10}$

\section{START STATINS IN HOSPITAL}

Against this background, and the recent demonstration that statins benefit male and female coronary heart disease patients up to 80 years of age provided their serum cholesterol is greater than $3.5 \mathrm{mmol} / \mathrm{l}$ at the start of treatment, ${ }^{11}$ an increasing body of evidence supports the view that these drugs should be started in hospital at the time of the acute coronary syndrome. Four observational studies ${ }^{12-15}$ and two randomised trials ${ }^{16}{ }^{17}$ suggest such a strategy will not only increase compliance ${ }^{12}{ }^{13}$ but also improve outcome. ${ }^{12-17}$ One of these studies, a quality improvement programme which focused on implementing secondary prophylactic medical treatment with lifestyle advice, increased statin prescription at discharge from $6 \%$ to $86 \%$ of myocardial infarction patients. ${ }^{12}$ Treatment rates one year after discharge were $10 \%$ and $91 \%$, respectively. These were associated with an increase in patients achieving a low density lipoprotein cholesterol concentration less than $2.6 \mathrm{mmol} / \mathrm{l}(6 \% \quad v \quad 58 \%)$ and a reduction both in recurrent myocardial infarction $(7.8 \% \mathrm{v}$ $3.1 \%)$ and total mortality $(7.0 \% v 3.3 \%)$. This achievement was all the more remarkable because the study was conducted as long ago as 1994.

In hospital initiation of lipid lowering therapy means that treatment is started when the minds of patients and their carers are concentrated on their cardiovascular risk, which in turn may strengthen the perception that this therapy is essential for the prevention of recurrent events. ${ }^{18}$ The lesson for us all is that we can make a difference if we are sufficiently determined to do so.

\section{REFERENCES}

1 Reid FDA, Cook DG, Whincup PH. Use of statins in the secondary prevention of coronary heart disease: is treatment equitable? Heart 2002:88:15-19.

2 Steg PG, lung B, Feldman L, et al. Impact of availability and use of coronary interventions on the prescription of aspirin and lipid lowering treatment after acute coronary syndromes. Heart 2002;88:20-4.

3 Majeed A, Moser K, Maxwell R. Age, sex and practice variations in the use of statins in general practice in England and Wales. J Public Health Med 2000:22:275-9.

4 Brady AJB, Oliver MA, Pittard JB. Secondary prevention in 24,431 patients with coronary heart disease: survey in primary care. $B M$ 2001;322:1463

5 The National Service Framework for Coronary Heart Disease. www.doh.gov.uk/nsf/coronary.htm

6 Fonarow GC, French WJ, Parsons LS, et al for the National Registry of Myocardial Infarction 3 Participants. Use of lipid lowering medications at discharge in patients with acute myocardial infarction: data from the national registry of myocardial infarction 3 . Circulation 2001;103:38-44

7 EUROASPIRE I and II Group. Clinical reality of coronary prevention guidelines: a comparison of EURO-ASPIRE I and II in 9 countries. Lancet 2001;357:995-1001

8 Pickin DM, McCabe CJ, Ramsay LE, et al. Cost effectiveness of HMG $\mathrm{CoA}$ reductase inhibitor (statin) treatment related to the risk of coronary heart disease and cost of drug treatment. Heart 1999;82:325-32.

9 McAlister FA, Lawson FME, Teo KK, et al. Randomised trials of secondary prevention programmes in coronary heart disease: a systematic review. BM 2001;323:957-62.

10 Isles C, Campbell N, Stuckey N. Secondary prevention of CHD and the National Service Framework: barriers to implementation. Cardiabetes 2001:1:11-17.

11 Medical Research Council/British Heart Foundation. Preliminary results of the MRC/BHF Heart Protection Study 2001. www.hpsinfo.or

12 Fonarow GC, Gawlinski A, Moughrabi S, et al. Improved treatment of coronary heart disease by implementation of a cardiac hospitalisation atherosclerosis management programme (CHAMP). Am J Cardiol 2001;87:819-22.

13 Muhlestein JB, Horne BD, Bair TL, et al. Usefulness of in hospital prescription of statin agents after angiographic diagnosis of coronary artery disease in improving continued compliance and reducing mortality. Am J Cardiol 2001;87:257-61.

14 Aronow HD, Topol EJ, Roe MT, et al. Effect of lipid lowering therapy on early mortality after acute coronary syndromes: an observational study. Lancet 2001;357:1063-8.

15 Stenestrand U, Wallentin L for the Swedish Register of Cardiac Intensive Care. Early statin treatment following acute myocardial infarction and one year survival. JAMA 2001;285:430-6.

16 Schwartz GG, Olsson AG, Ezekowitz MD, et al. The effects of atorvastatin on early recurrent ischaemic events in acute coronary syndromes. The MIRACL study: a randomised controlled trial. JAMA 2001;285:1711-18.

17 Arntz H, Agrawal R, Wunderlich W, et al. Beneficial effects of pravastatin ( \pm cholestyramine/niacin) initiated immediately after a coronary event. The randomised lipid coronary artery disease (LCAD) study. Am J Cardiol 2000;86:1293-8.

18 Fonarow GC, Ballantyne CM. In hospital initiation of lipid lowering therapy for patients with coronary heart disease: the time is now. Circulation 2001; 103:2768-70.

\section{FROM BM JOURNALS}

\section{HLHS: first operative hurdle is the worst}

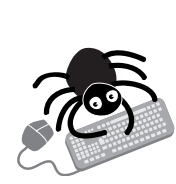

Please visit the Heart website [www.heartinl.com] for link to this full article.

edium term outlook is good for babies surviving stage I reconstructive surgery for antenatally diagnosed hypoplastic left heart syndrome (HLHS). Reconstructive palliative surgery has greatly Iimproved the outlook for this condition and makes antenatal diagnosis even more important to help parents make informed decisions based on up to date results.

Andrews et al report outcome data for antenatally diagnosed classic HLHS in the largest series so far174 babies from Guy's Hospital, London, five from other units, (and nine postnatal diagnoses). Of these, 64 babies underwent stage I of a three stage surgical palliation, which ultimately directs systemic venous return straight to the pulmonary arteries and allows the right ventricle to act solely as the systemic pump.

Deaths associated with stage I were high: 30 within the first month (three during the operation, 18 within 24 hours, seven during the first week, and two at three weeks) and one at six weeks. Just over half the babies survived $(52 \%, 33 / 64)$. All 29 babies who underwent stage II survived except two, and all 10 who underwent stage III survived. One child had a heart transplant, and 16 were awaiting stage III. Overall survival was $48 \%(31 / 64)$, or $49 \%(27 / 55)$ for antenatal diagnoses. Three children had neurological problems at follow up.

Hopefully, future improvements in surgical technique and perioperative intensive care will continue to increase the chances of survival and reduce the risk of long term complications.

A Archives of Disease in Childhood 2001;85:474-477 